\title{
Distortion Reduction Strategies for PCD Runout of Cam Shaft Gear
}

\author{
V. Kulkarni ${ }^{1 *}$, M. Dhanvijay ${ }^{2}$ \\ ${ }^{1}$ DY Patil College of Engineering, Akurdi, Pune, Savitribai Phule Pune University, India \\ ${ }^{2}$ Assistant Professor, College of Engineering, Pune, India \\ \{kulkarnivinay@ rediffmail.com\}
}

\begin{abstract}
The purpose of heat treatment will be to modify the structure of material and relieve the stresses set up in the material. Rejection of Gears is susceptible, after heat treatment process, due to excess distortion. This leads to risk of getting PCD Runout fired owing to its chronicle failure. Analysis of this variation needs data collection methodology and systematic study of process capability to achieve low losses. Cam Shaft Gear is a vital component in Engine Assembly of automobile and is responsible for fuel injection and power generation in vehicle. In this paper, an attempt is made to formulate research framework to achieve process capability of Cam shaft Gear distortion issues in form of PCD runout, after heat treatment process, by enhancing defect free strategies for reduction of PCD runout. The results showed, enhanced process capability after modification in bar design and correcting quenching fluid velocity.
\end{abstract}

Keywords:Camshaft Gear, PCD Runout, Distortion, Process Capability

\section{Introduction}

Gear generating involves gear cutting through the relative motion of a rotating cutting tool and the generating, or rotational, motion of the work piece. The two primary generating processes are hobbing and shaping. Hobbing uses helically fluted cutting tool (HOB) and fed axially to a rotating workpiece, across the gear blank. Hobbing can be performed on single gear blank, but effectively allows stacking of multiple workpieces, increasing production rate. Based on hardness of gears, manufacturing of gears can be classified into hard stage and soft stage as shown in Fig. 1.

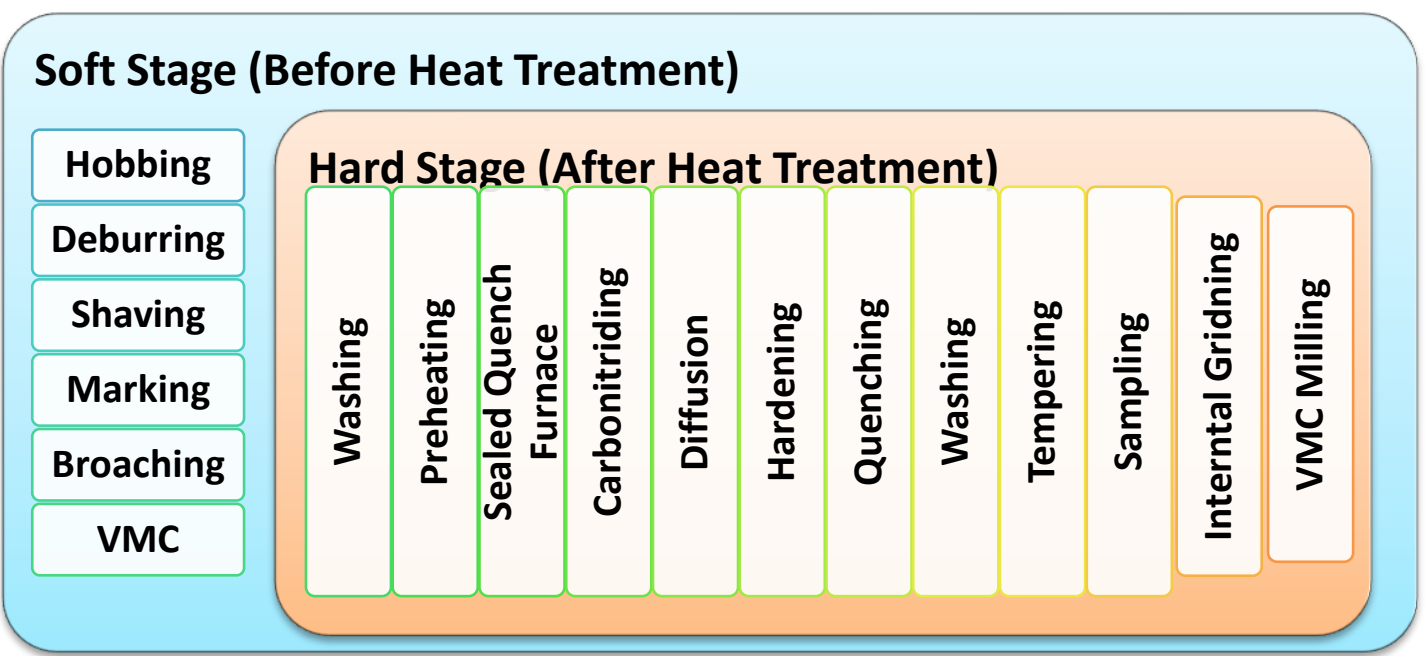

Fig. 1. Process Flow for Cam Shaft Gear Manufacturing

B. Iyer, S. Nalbalwar and R. Pawade (Eds.)

ICCASP/ICMMD-2016. Advances in Intelligent Systems Research.

Vol. 137, Pp. 7-14.

(C) 2017. The authors - Published by Atlantis Press 
Soft Stages of Gear before heat treatment includes manufacturing and finishing steps. After treatment of gearsincludes stage wise heat treatment based advancements such as carbonising, diffusion and hardening. This step aims at smoothing function of gears with reliability during operations.

\subsection{Description of Existing Manufacturing Setup}

Heat Treatment is looked as an operation or combination of operations involving the controlled heating and cooling of metal in the solid state for the purpose of obtaining specific properties. The purpose of heat treatment will be to modify the structure of material and relieve the stresses set up in the material. For this purpose, Sealed Quench Furnaces (SQF) is used with oil quenching media. The gears are loaded on the base tray and fixture, with a total charge capacity weight $1000 \mathrm{~kg}$ is loaded in the furnace heating chamber with an automated procedure. Charge is heated to 9000Cin the heating chamber in the sealed and controlled atmosphere as per the cycle setting. On completion of heating cycle the charge is automatically removed from the heating chamber and brought in the front chamber where it is quenched in the oil bath within 18 seconds. After completion of quenching the charge is removed from the furnace and washed in the washing machine. Quenching of steel involves the rapid cooling of austenite to transform it into the hard structure-martensite.

\subsubsection{Part Description}

Cam shaft gear of having outer diameter $156.7 \mathrm{~mm}$ and inner diameter $33.05 \mathrm{~mm}$ with chamfer length 1.4 , depth 9.90, GD \& T //0.02, total thickness 21.70 and free from dent, burr, damage and dust is used for manufacturing.

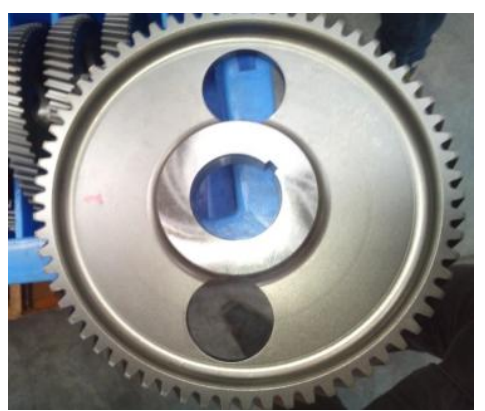

Fig2. Camshaft Gear with a Keyway at centre

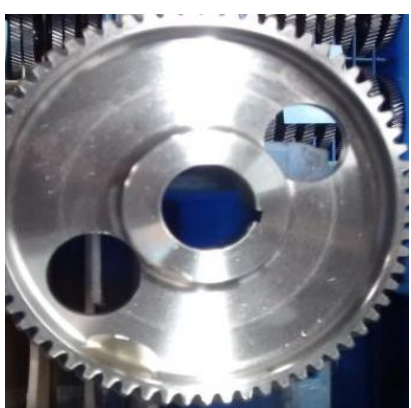

Fig 3. Back Side of Gear

Its other specifications are noted in table 1

Table 1 Technical Characteristics of Camshaft Gear

\begin{tabular}{|c|c|}
\hline \multicolumn{2}{|c|}{ Technical Characteristics } \\
\hline Metallurgical Composition & Steel Grade $-20 \mathrm{MnCr}$, Carbon Steel \\
\hline Chemical Composition & C-0.18, Mn-1.14, Cr-1.05, Ni-0.028, MO-0.003, P-0.012, S-0.029, Si-0.18, \\
Al-0.034
\end{tabular}




\begin{tabular}{|c|c|}
\hline \multicolumn{2}{|c|}{ Technical Characteristics } \\
\hline Micro Structure & Uniform Normalized of ferrite and pearlite \\
\hline Surface Hardness & $81-83 \mathrm{HRA}$ \\
\hline Finish Weight & $0.324 \mathrm{~kg}$ \\
\hline Operational Description & $\begin{array}{c}\text { It has two pocket holes that help in bolting during assembly. } \\
\text { It has a rectangular shaped lug provided on its back side. } \\
\text { The fitted assembly of gear on camshaft in closed housing is provided with } \\
\text { sensor. During the operation when gear comes funder sensor, fuel injection } \\
\text { occurs; Fuel injection to the engine is totally dependent on the relative } \\
\text { position of lug and sensor, resulting in a cyclic process. }\end{array}$ \\
\hline
\end{tabular}

The heat treatment requirements of Camshaft Gear are noted in Table 2

Table 2 Heat Treatment Details of Camshaft Gear

\begin{tabular}{|c|c|c|c|}
\hline Process & Temperature (0C) & Time (Minutes) & Carbon Potential \% \\
\hline Preheating & 480 & 60 & - \\
\hline Carbonitriding & 870 & 50 & 0.95 \\
\hline Diffusion & 870 & 10 & 0.85 \\
\hline Hardening & 830 & 30 & 0.75 \\
\hline Oil & 130 & - & 550 \\
\hline Tempering & 160 & 150 & \\
\hline \multicolumn{2}{|}{ Oil make - HiQuench MT 650 } \\
\hline
\end{tabular}

\subsubsection{Expected Outcome of Gears Quality}

The gears produced should be free from distortion. Distortion is an irreversible and unpredicted changes in shape and size, phase changes, changes in hardness, microstructure and residual stresses of the component during processing from heat treatment and from temperature variations and loading in service. Section 2 reports literature survey result with this approach.

\section{Literature Survey}

Number of researchers made attempts to form research framework to address the problem of Quality of Gears. Few relevant studies on addressing distortion problems are as per following.

Suleyman Saritas and et al (2002) concluded that Pores in sintered P/M steels influence their thermal response and thereby hardenability.

BL Ferguson and et al (2005) found that hardening process leads to geometric distortion and recommends optimized method to derive the phase transformation kinetics parameters from dilatometry experiments. They further recommend specific model preparation to predict distortion and residual stresses by experimental method.

Christian Bahnsen and et al (2005) carried out distortion study for $20 \mathrm{MnCr} 5$ component and concluded that internal stresses act as major contributor.

Anil Kumar Sinha, Bohn Piston Division (2014) carried out distortion study and concluded that faulty heat treatment practices, deficiency in the grade of steels used, part defect, improper grinding and poor part design are contributory factors.

Jeevan P. George, et al (2014) carried out research work on gear treatment process by simple fixture and recommends better cooling mechanism, reduction of gear weight and improved fixture to hold gears during the treatment. However, fixture itself acts as another interface for cooling mechanism to be addressed leading to more complex formation of research framework.

V. Khade, et al (2015) carried out research work case hardened steel gears and found that distortion is characterized by uneven hardening, formation of soft spots, increase in warpage during quenching and increase in case depth. They concluded use of sealed oil in quench furnace is the predominant cause of distortion. 
From this review, it is evident that specific component should be experimentally analyzed and statistically minimize effects of distortion in specific environment. It is therefore, relevant that distortion studies depicting PCD runout should be carried out.

\section{Problem Identification}

The Camshaft gear part produced is susceptible for distortion depicting in PCD runout. It is found that this problem is mainly occurring in a certain lot. As one part is costing about 400/-, it is critical to find the systems of associated errors and eliminate it.

Fig. 4. shows monthwise rejection of parts due to PCD runout.

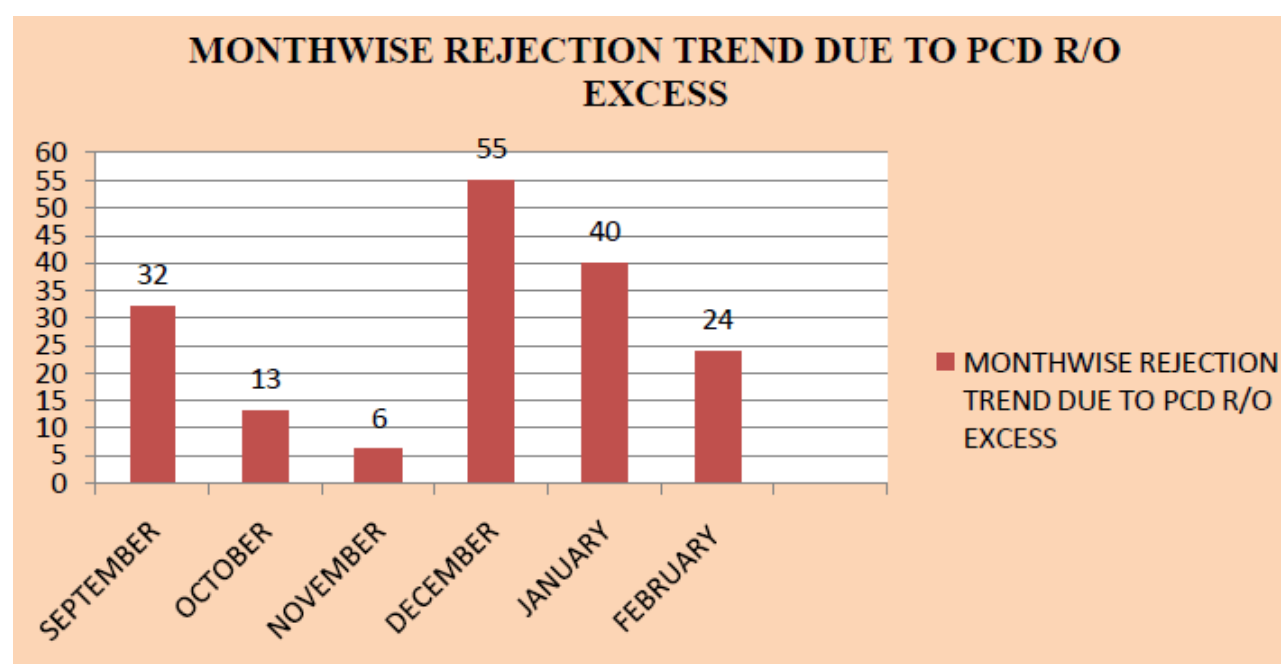

Fig. 4. Monthwise rejection due to PCD

The corresponding cost of Poor Quality is demonstrated in Table 3

Table 3 Cost of Poor Quality

\begin{tabular}{|c|c|c|}
\hline Sr. No. & Description & Poor Quality Parameter \\
\hline 1. & Number of parts rejected for December & 55 \\
\hline 2. & Number of pieces scrapped last month & 55 \\
\hline 3. & Number of pieces scrapped last month & 0 \\
\hline 4. & Scrap Cost Per Piece & $398 /-$ Approx \\
\hline 5. & Rework Cost Per Piece & 0 \\
\hline 6. & Total Scrap Cost & $21980 /-$ \\
\hline 7. & Total Rework Cost & $21980 /-$ \\
\hline 8. & Total Rejection Cost & $262680 /-$ \\
\hline 9. & Extrapolated Total Rejection Cost in a year & \\
\hline
\end{tabular}

\subsection{Experimental Study}

A study is conducted on the charge to measure and find out amount of distortion occurred after the quenching process.

\section{Cause and Effect Diagram}

The cause and effect diagram is plotted to analyze the effect of PCD Runout Problem in form of distortion

\subsubsection{Formulation of Hypothesis in valid/invalid formation from Cause and Effect Diagram}


The hypothesis Identification based on Cause and Effect Diagram is done as indicated herewith.

Hypothesis 1 - DOP

Hypothesis 3-Flatness not Ok
Hypothesis 2 - Fixture not ok

Hypothesis 4- Heat Treatment Cycle not OK

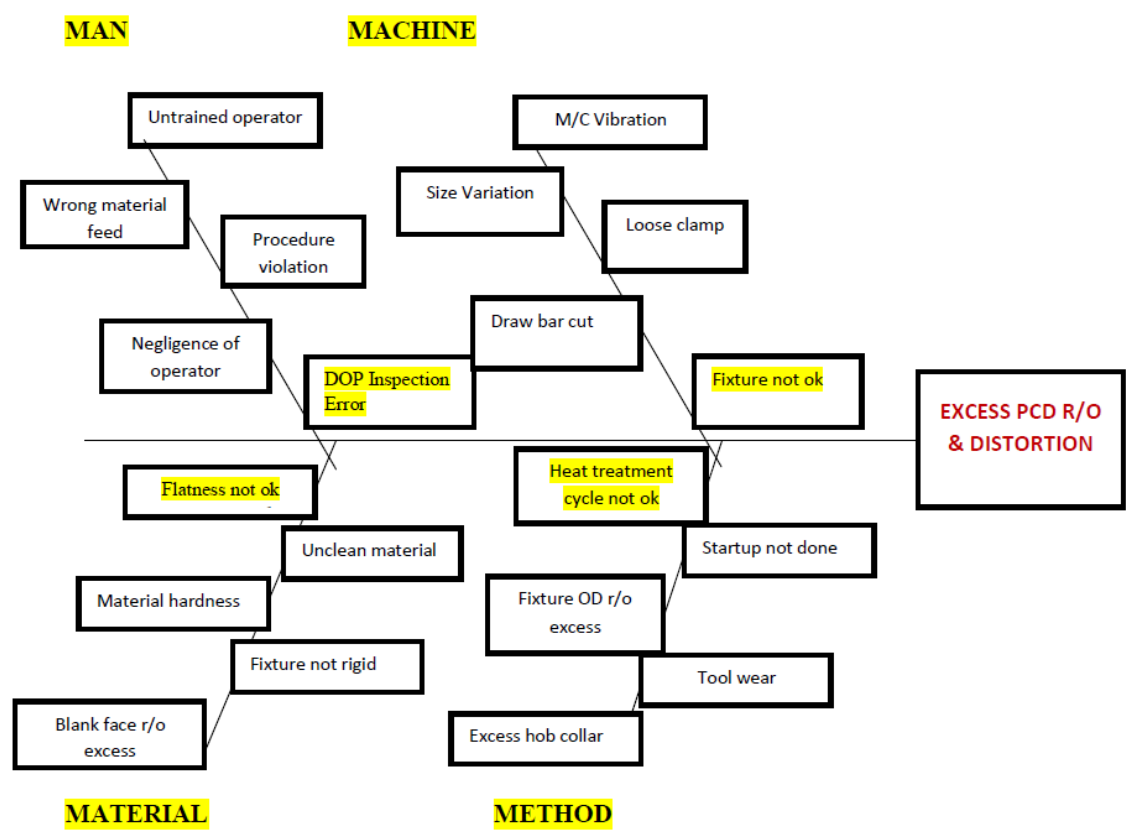

Fig. 5. Cause and Effect Diagram of PCD Runout

Table 4 Hypothesis Conclusion

\begin{tabular}{|l|c|l|c|}
\hline $\begin{array}{c}\text { Sr. } \\
\text { No. }\end{array}$ & Probable Cause & Test Observations & Conclusion \\
\hline 1. & DOP Inspection Error & MSA and Gauge R \& R if acceptable & $\begin{array}{c}\text { Hypothesis is } \\
\text { invalid }\end{array}$ \\
\hline 2. & Fixture not ok & Continuous 50 parts checked and PCD run out is ok & $\begin{array}{c}\text { Hypothesis is } \\
\text { invalid }\end{array}$ \\
\hline 3. & Flatness not ok & $\begin{array}{l}\text { Out of 18 parts 6 good parts and 6 bad parts are considered } \\
\text { and relation of RCD Runout with flatness is carried out }\end{array}$ & $\begin{array}{c}\text { Hypothesis is } \\
\text { invalid }\end{array}$ \\
\hline 4. & $\begin{array}{c}\text { Heat Treatment Cycle } \\
\text { not ok }\end{array}$ & $\begin{array}{l}\text { 18 piece study and 150 piece study done with Before Heat } \\
\text { Treatment, parts found ok and sent for heat treatment and } \\
\text { were inspected and 65\% parts were not found ok }\end{array}$ & $\begin{array}{c}\text { Hypothesis is } \\
\text { valid }\end{array}$ \\
\hline
\end{tabular}


Table 5 Gauge R \& R Data

\begin{tabular}{|c|c|c|c|c|c|c|c|c|c|c|c|c|c|}
\hline \multicolumn{3}{|c|}{ PART NAME } & \multicolumn{3}{|c|}{ camshaft engine gear } & \multicolumn{2}{|c|}{ PART NO. } & \multicolumn{2}{|c|}{ MG002268 } & \multicolumn{2}{|c|}{ UPPER TOL .LIMIT } & \multicolumn{2}{|r|}{90} \\
\hline \multicolumn{3}{|c|}{ GAUGE / EQUIPMENT NAME } & \multicolumn{3}{|c|}{ rolling tester } & \multicolumn{2}{|c|}{$\begin{array}{l}\text { GAUGE / } \\
\text { EQUIP.NO. }\end{array}$} & & & \multicolumn{2}{|c|}{$\begin{array}{l}\text { LOWER TOL. } \\
\text { LIMIT }\end{array}$} & \multicolumn{2}{|r|}{0} \\
\hline \multicolumn{3}{|c|}{$\begin{array}{c}\text { GAUGE / EQUIP. LEAST } \\
\text { COUNT }\end{array}$} & \multicolumn{3}{|c|}{0.01} & \multicolumn{2}{|c|}{ CHARACTERISTIC } & \multicolumn{2}{|c|}{ DOP(FINAL) } & \multicolumn{2}{|c|}{ TOLERANCE } & \multicolumn{2}{|r|}{90} \\
\hline \multicolumn{14}{|c|}{ DATA COLLECTION } \\
\hline \multirow{18}{*}{ 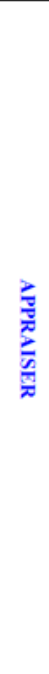 } & \multicolumn{2}{|c|}{$\begin{array}{c}\text { NO. OF } \\
\text { TRIALS/PARTS }\end{array}$} & 1 & 2 & 3 & 4 & 5 & 6 & 7 & 8 & 9 & 10 & AVERAC \\
\hline & \multirow{5}{*}{ 竞 } & 1 & 70.000 & 72.000 & 75.000 & 71.000 & 74.000 & 71.000 & 70.000 & 72.000 & 75.000 & 72.000 & 72.2 \\
\hline & & 2 & 68.000 & 72.000 & 73.000 & 75.000 & 75.000 & 70.000 & 74.000 & 75.000 & 80.000 & 71.000 & 73.3 \\
\hline & & 3 & 70.000 & 70.000 & 72.000 & 74.000 & 71.000 & 72.000 & 73.000 & 76.000 & 78.000 & 74.000 & 73 \\
\hline & & AVG.(kl) & 69.3333 & 71.3333 & 73.3333 & 73.3333 & 73.3333 & 71 & 72.3333 & 74.3333 & 77.6667 & 72.3333 & 72.833333 \\
\hline & & RANGE (kl) & 2.00000 & 2.00000 & 3.00000 & 4.00000 & 4.00000 & 2.00000 & 4.00000 & 4.00000 & 5.00000 & 3.00000 & 3.30000 \\
\hline & \multicolumn{2}{|c|}{$\begin{array}{c}\text { NO. OF } \\
\text { TRIALS/PARTS }\end{array}$} & 1 & 2 & 3 & 4 & 5 & 6 & 7 & 8 & 9 & 10 & AVERAC \\
\hline & \multirow{5}{*}{$\begin{array}{l}\overrightarrow{\tilde{W}} \\
\text { : } \\
\mathbb{E}\end{array}$} & 1 & 65.000 & 68.000 & 73.000 & 72.000 & 74.000 & 68.000 & 73.000 & 70.000 & 78.000 & 68.000 & 70.9 \\
\hline & & 2 & 70.000 & 69.000 & 73.000 & 77.000 & 72.000 & 75.000 & 74.000 & 74.000 & 81.000 & 70.000 & 73.5 \\
\hline & & 3 & 68.000 & 73.000 & 76.000 & 68.000 & 75.000 & 74.000 & 72.000 & 70.000 & 80.000 & 71.000 & 72.7 \\
\hline & & AVG.(k2) & 67.6667 & 70 & 74 & 72.3333 & 73.6667 & 72.3333 & 73 & 71.3333 & 79.6667 & 69.6667 & 72.366660 \\
\hline & & RANGE (k2) & 5.00000 & 5.00000 & 3.00000 & 9.00000 & 3.00000 & 7.00000 & 2.00000 & 4.00000 & 3.00000 & 3.00000 & 4.40000 \\
\hline & \multicolumn{2}{|c|}{$\begin{array}{c}\text { NO. OF } \\
\text { TRIALS/PARTS }\end{array}$} & 1 & 2 & 3 & 4 & 5 & 6 & 7 & 8 & 9 & 10 & AVERAC \\
\hline & \multirow{5}{*}{ 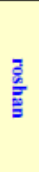 } & 1 & 65.000 & 71.000 & 75.000 & 74.000 & 75.000 & 71.000 & 70.000 & 74.000 & 76.000 & 70.000 & 72.333333 \\
\hline & & 2 & 68.000 & 75.000 & 74.000 & 72.000 & 72.000 & 73.000 & 72.000 & 73.000 & 79.000 & 74.000 & 73.777777 \\
\hline & & 3 & 67.000 & 72.000 & 71.000 & 70.000 & 76.000 & 75.000 & 69.000 & 73.000 & 77.000 & 71.000 & 72.1 \\
\hline & & AVG.(k3) & 66.6667 & 72.6667 & 73.3333 & 72 & 74.3333 & 73 & 70.3333 & 73.3333 & 77.3333 & 71.6667 & 72.466666 \\
\hline & & RANGE (k3) & 3.00000 & 4.00000 & 4.00000 & 4.00000 & 4.00000 & 4.00000 & 3.00000 & 1.00000 & 3.00000 & 4.00000 & 3.40000 \\
\hline
\end{tabular}

Table 6 Summary Results of Gauge R \& R Studies

RESULTS / EVALUATION

\begin{tabular}{|c|c|}
\hline \multicolumn{2}{|l|}{ RESULTS / EVALUATION } \\
\hline $\begin{array}{l}\text { REPEATABILITY (EQUIPMENT VARIATION) } \\
\mathrm{EV}=2 \times \mathrm{K} 1\end{array}$ & 11.28500 \\
\hline $\begin{array}{l}\text { REPRODUCABILITY (APPRAISER VARIATION) } \\
\mathrm{AV}=\square\left\{(8 \mathrm{DIFF} \times \mathrm{K} 2)^{2}-\left(\mathrm{EV}^{2} / \mathrm{nr}\right)\right\}\end{array}$ & -2.98504 \\
\hline $\begin{array}{l}\text { REPEATABILITY \& REPRODUCABILITY (R \& R) } \\
\text { R \& R = } \square\left(\mathrm{EV}^{2}+\mathrm{AV}^{2}\right)\end{array}$ & 11.67312 \\
\hline $\begin{array}{l}\text { PART VARIATION }(\mathrm{PV}) \\
\mathrm{PV}=\mathrm{R} \mathrm{p} \mathrm{K} 3\end{array}$ & 16.74000 \\
\hline $\begin{array}{l}\text { TOTAL VARIATION (TV) } \\
T V=\square\left(R \& \mathrm{R}^{2}+\mathrm{PV}^{2}\right)\end{array}$ & 20.40807 \\
\hline $\begin{array}{l}\text { \% EQUIPMENT VARIATION (EV) } \\
\% \mathrm{EV}=100 \times\{\mathrm{EV} \div \mathrm{TT}\}\end{array}$ & $12.54 \%$ \\
\hline $\begin{array}{l}\text { \% APPRAISER VARIATION (AV) } \\
\% \mathrm{AV}=100 \times\{\mathrm{AV} \div \mathrm{TT}\}\end{array}$ & $-3.32 \%$ \\
\hline $\begin{array}{l}\text { \% REPEATABILITY \& REPRODUCABILITY } \\
\% \mathrm{R} \& \mathrm{R}=100 \times\{\mathrm{R} \& \mathrm{R} \div \mathrm{TT}\}\end{array}$ & $12.97 \%$ \\
\hline $\begin{array}{l}\text { \% PART VARIATION }(\mathrm{PV}) \\
\% \mathrm{PV}=100 \times\{\mathrm{PV} \div \mathrm{TT})\end{array}$ & $18.60 \%$ \\
\hline
\end{tabular}

The noted part variation if $18.60 \%$ and Repeatability and Reproducibility is $12.97 \%$. The total variation from $\mathrm{R}$ $\& \mathrm{R}$ is conditionally accepted if it is below $20 \%$ which indicates that the measurement system is capable and can be used as decision making process.

The variation in flatness with respect to PCD runout is observed for total 10 parts (C10).From fig 6, it is evident that flatness variation is not affecting PCD Runout and their after distortion of workpiece. 18 jobs are inspected for PCD runout before modification at existing systems. The outlier test is conducted for these 18 jobs within value of $0.04 \mathrm{~mm}$ for PCD run out at soft stage and $0.09 \mathrm{~mm}$ for PCD runout at hard stage.The result is indicated in Fig 7. 


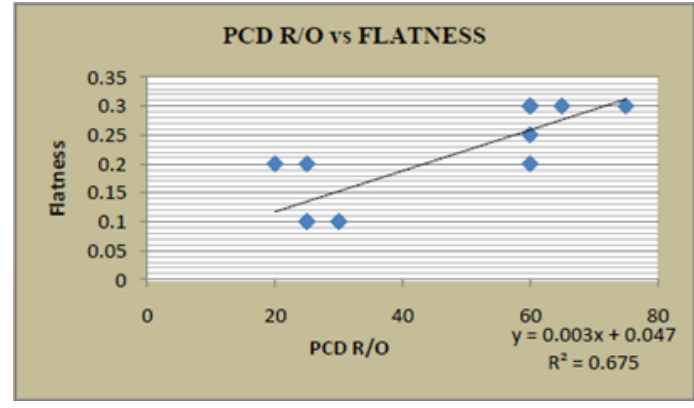

Fig. 6. Relation of PCD runout with Flatness


Fig. 7. PCD Runout for 18 Jobs

Fig. 8. Process Capability of Existing System

Fig.7 indicates higher PCD runouts in soft stage rather than hard stage. The hard stage process capability report for PCD runout is occurring due to defects induced in soft stage.

The process Capability study indicates that parts are out of upper specification limit. The Cpk and Ppk values are negative (-0.05 and -0.04) indicating that the process mean falls outside specification limits as the process is producing a large proportion of defective output.

\section{Modifications in Process to improve process capability}

For the heat treatment process, gears are loaded on a round bar in a quenching stand with a batch of 480 parts. The single round bar was used in tank to pass through the centre hole of gear which often leads to uneven vibrations causing distortion.

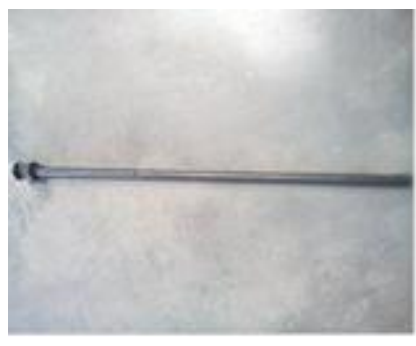

Fig. 9. (a) Round Bar

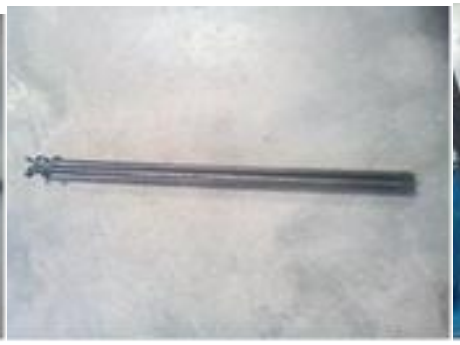

Fig. 9. (b) Star Bar

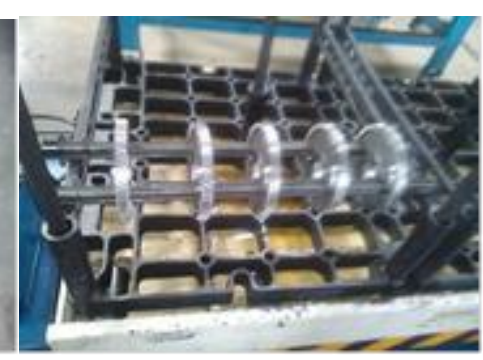

Fig. 9. (c) Gear Loading Stand

To overcome this distortion problem 2 star bars are loaded along alternative holes instead of round bar at centre hole as shown in fig 9 . The star bar provides stability to the gear, thereby reducing vibrations and distortions. In quenching process, oil is preferred than air. The flow of oil therefore is a vital parameter as it affects phase transformation. Increase in fluid velocity will enable the cooling rate at the center of the component exceeds the critical cooling rate. Therefore, a high speed accelerate quenching oil is recommended for usage with $1.665 \mathrm{~m} / \mathrm{s}$ velocity, rather than $1.491 \mathrm{~m} / \mathrm{s}$ which was already used, due to higher availability of speed step in quenching pump. 
The PCD runout is once again checked after modification as demonstrated in fig 10.

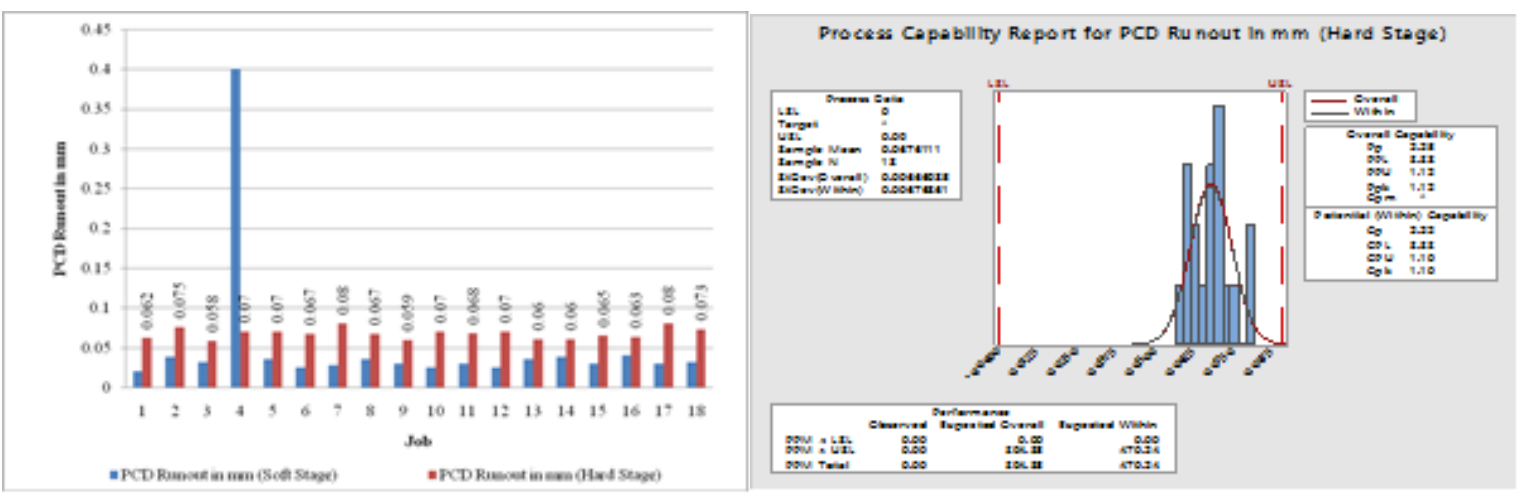

Fig. 10. PCD Runout after modification

Fig. 11. Process Capability after modification

The Cpk and Ppk values are in positive (+) indicates that the process mean falls within the specification limits as the process is not producing any defective input. Therefore, it can be concluded that the process spread is within the specification spread.

\section{Conclusions}

1. The experimental framework presented in this paper helps to set the maximum and minimum limit for quenching speed based on process capability improvement by modifications from round bar to star bar. Other conclusions are as per following

2. The flatness variation is not affecting PCD runout and distortion of workpiece.

3. The distortion of gears in form of PCD runout are caused by heat treatment process and it can be reduced by

4. Modification of Round Bar design into Star Bar Arrangement

5. Inadequate support during the heat-treatment cycle, poorly designed bars and quenching fixtures may cause distortion. Fixtures for holding finished parts or assemblies during heat treatment may be either support or restraint type to control dimensional relations during aging.

6. Correct Quenching oil temperature and flow rate selection

7. Poor selection of quenchant with desirable properties, high speed fluid velocity, uniform temperature of oil and adequate agitation during hardening results in minimum distortion. Change in Fluid velocity from 1.491 $\mathrm{m} / \mathrm{s}$ to $1.665 \mathrm{~m} / \mathrm{s}$, gradual reduction in PCD run out was observed.

\section{References}

[1] V. Khade, M. S. Ramgir, Study of Gear Teeth Distortions Due to Heat Treatment, International Journal of Scientific and Technology Research, Volume 4, Issue 02, February 2015, 74-79

[2] Jeeven P. George, Justin Koshy, Biju cherian abrasham, Distortion Reduction in Gear Heat Treatment Process by a Simple Fixture, International Journal of Emerging Technology and Advanced Engineering, Volume 4, Issue 11, November 2014, 306-312

[3] Suleyman Saritas, Roger D. Doherty and Alan Lawley, Effect of Porosity on the hardenability of P/M Steels, Research Gate, January 2002

[4] Anil Kumar Sinha, Bhon Piston Division, Defects and Distortion in Heat-Treated Parts, ASM Handbook, Volume 4, Heat Treating, ASM Handbook Committee,601-619

[5] Christian Bahnsen, Brigitte Clausen, Franz Hoffmann, Hans-Werner Zoch, Influence of Carburising on Distortion Behaviour, 1st International Proceedings on Distortion Engineering 2005, 228-234,

[6] B.L. Ferguson, Z. Li, A.M. Freborg, Modelling heat treatment of steel parts, Computational Materials Science, Volume 34, Issue 3, November 2005, 274-281 